\title{
Environmental Loss Characterization of an Advanced Stirling Convertor (ASC-E2) Insulation Package using a Mock Heater
}

International Energy Conversion Engineering Conference August 1, 2011

\author{
Nicholas A. Schifer \\ NASA Glenn Research Center \\ RPT - Thermal Energy Conversion Branch
}




\section{Net Heat Input Session Presentations}

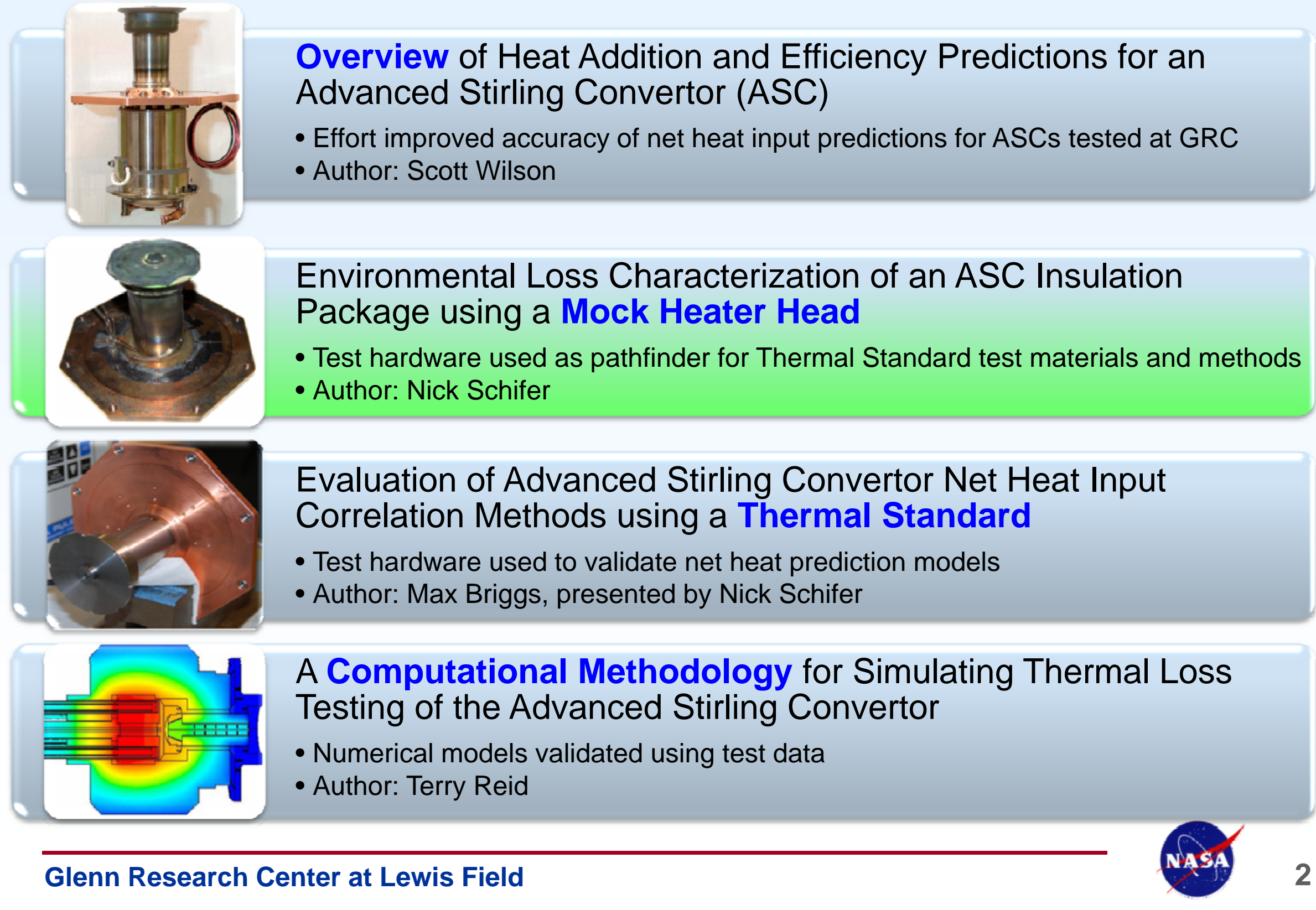




\section{Why is Net Heat Input Needed?}

- Problem: Net Heat Input cannot be measured directly during operation

- Net heat input is a key parameter needed in prediction of efficiency for convertor performance

- $\quad$ Efficiency = Electrical Power Output (Measured) divided by Net Heat Input (Calculated)

- Efficiency is used to compare convertor designs and trade technology advantages for mission planning

ASRG developed by Department of Energy and Lockheed Martin

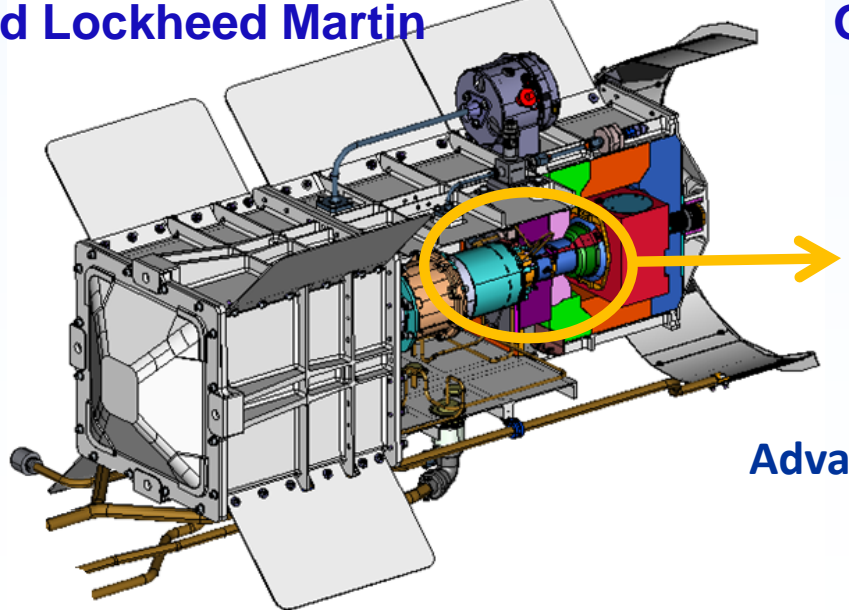

ASC developed by Sunpower, Inc. \& NASA Glenn Research Center

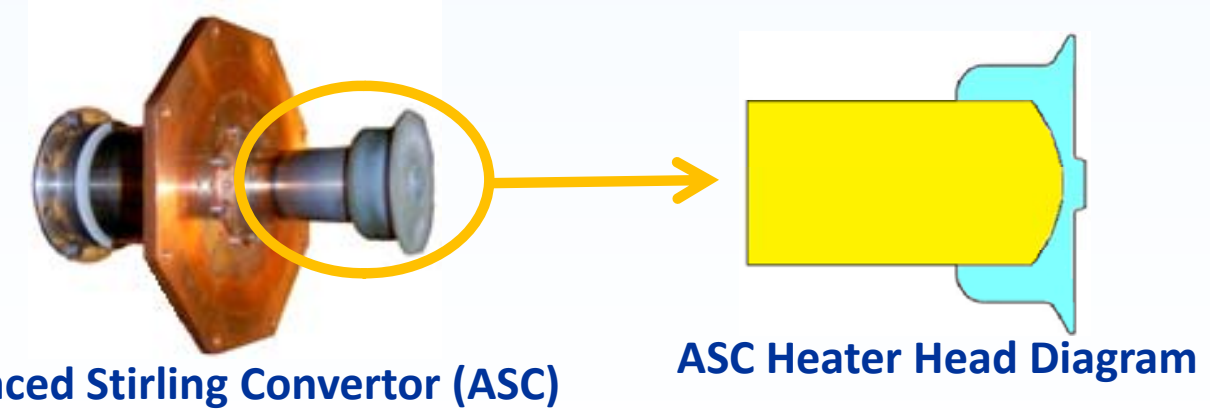

Advanced Stirling Radioisotope Generator (ASRG) 


\section{What is Net Heat Input?}

- Net Heat Input is heat energy required for thermodynamic cycle heat addition + parasitic heat transfer losses inherent to heat engines

Environment

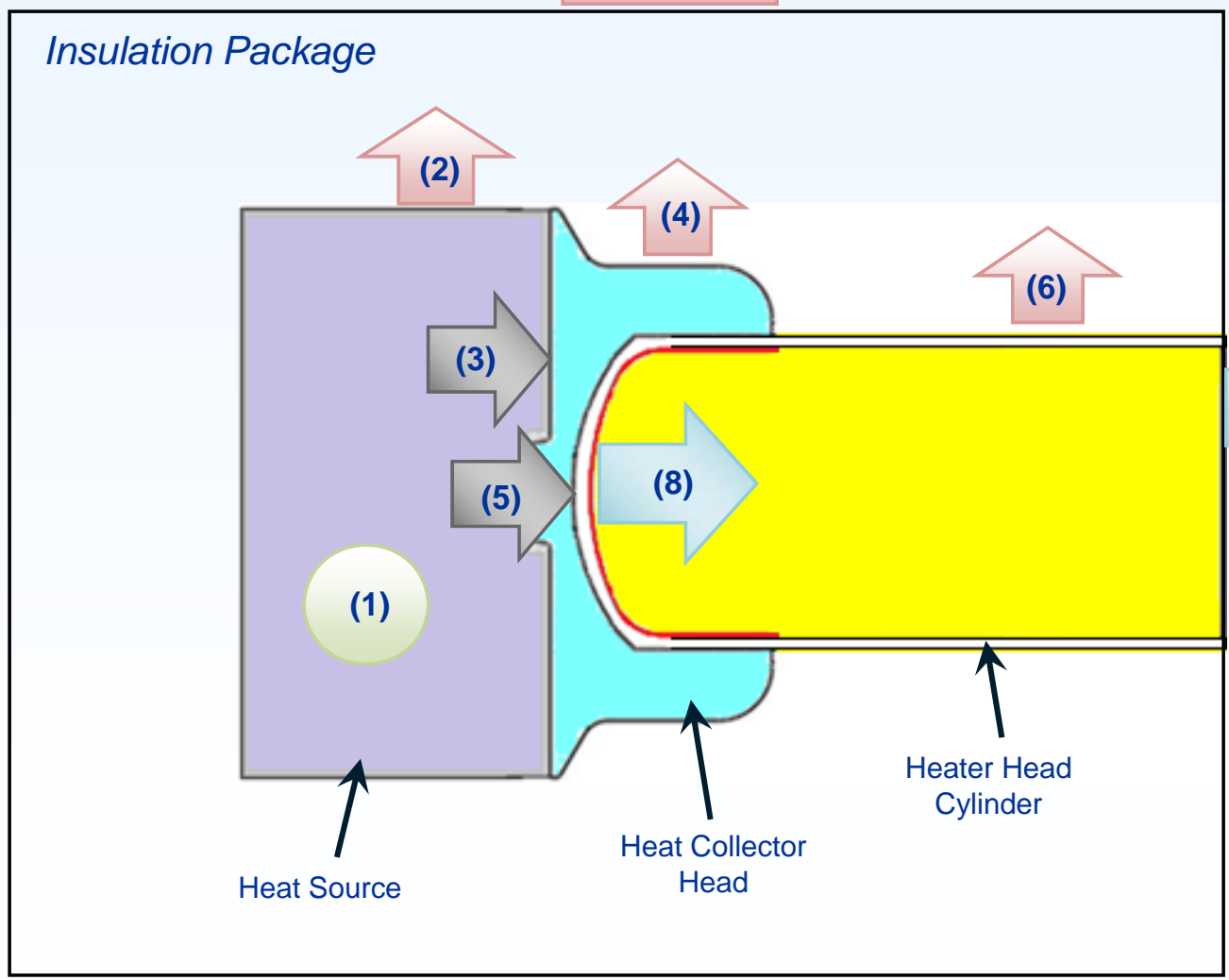

(1) Gross heat input to Heat Source

(2) to Insulation Package

(3) to Heat Collector Head

(4) to Insulation Package

(5) to Heater Head Cylinder

(6) to Insulation Package

(7) to Cold End of convertor

(8) to Stirling cycle 


\section{Outline}

- Problem Statement

- Introduction to the Mock Heater Head

- Role of the Mock Heater Head - Pathfinder

- Test Configuration

- Calculations

- Testing

- Heat Flow Paths

- GRCop-84 conducting rod

- Thermal Imaging

- Conclusions 


\section{Problem Statement}

During Insulation Loss

Testing (Non-operating)

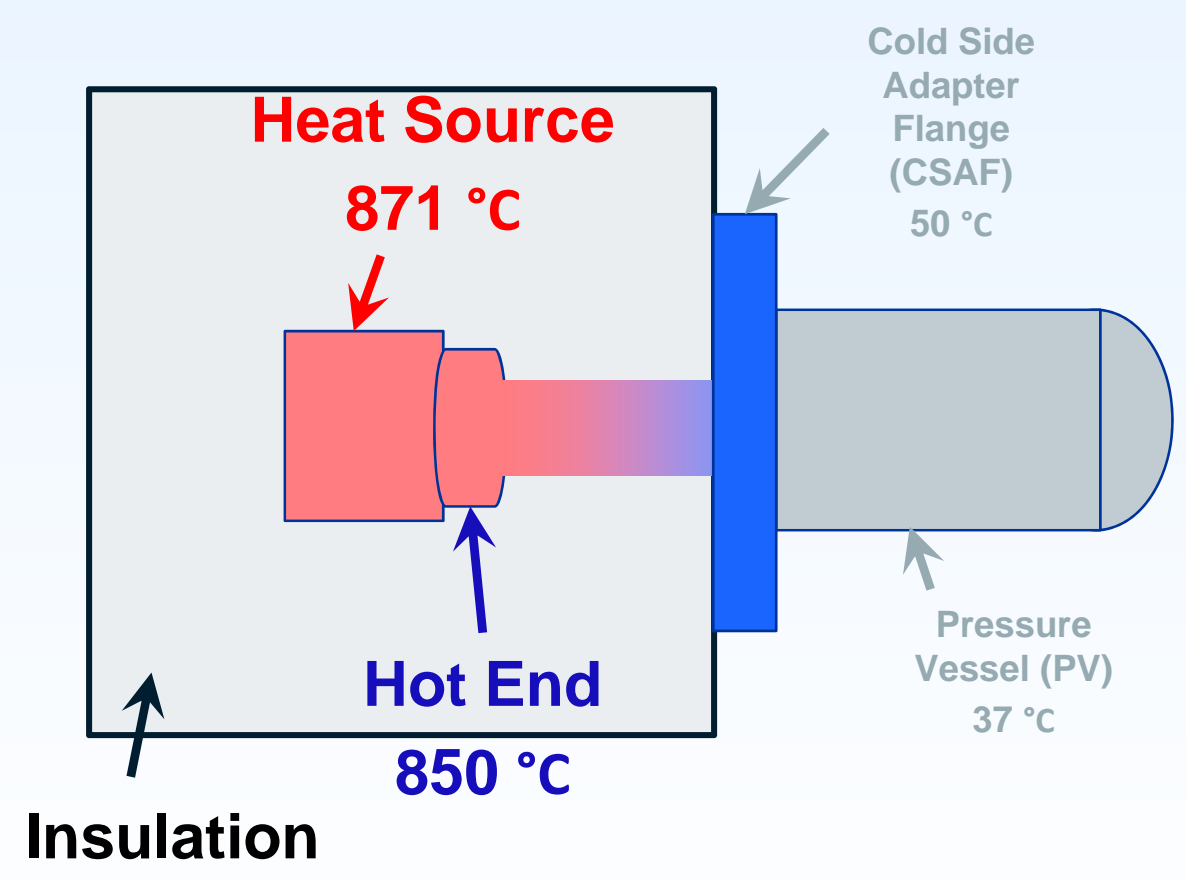

During Normal Operation

(Operating)

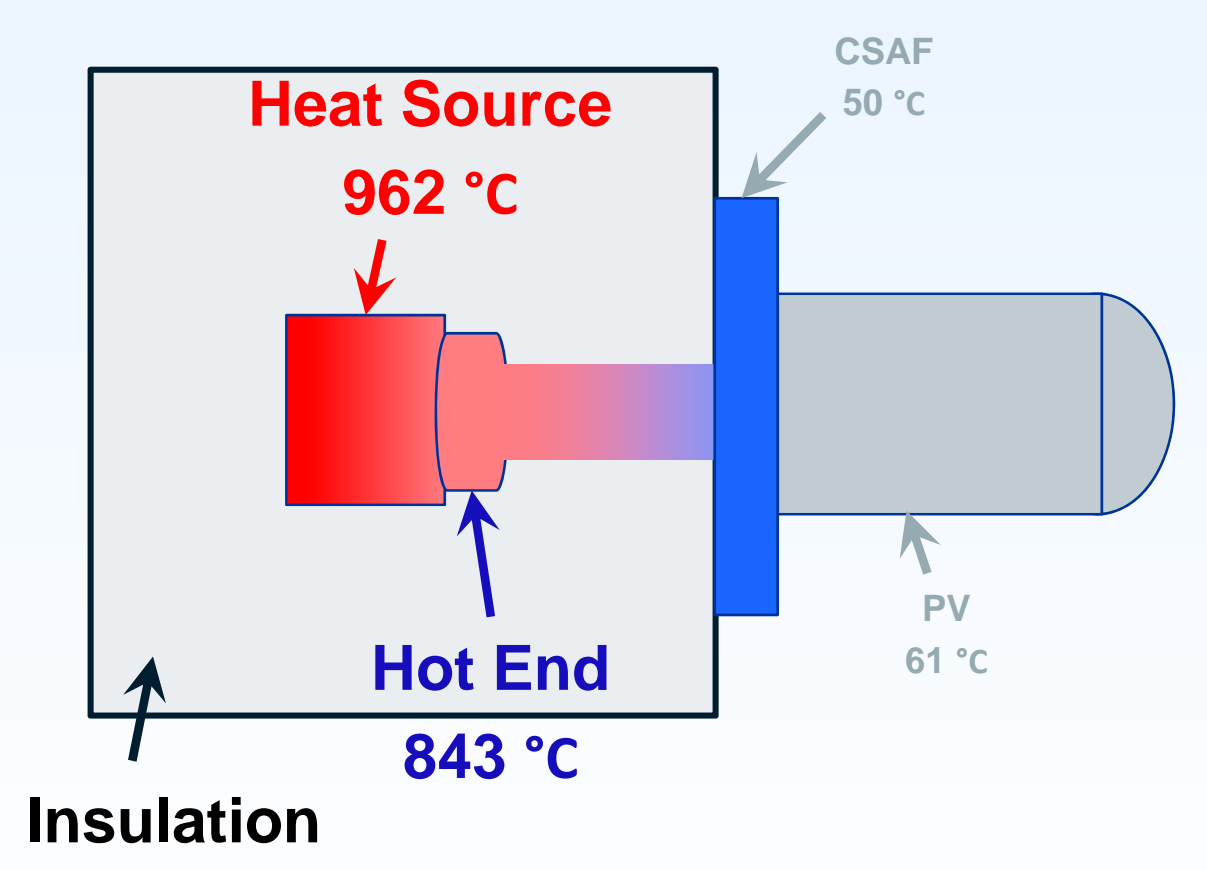

Thermal gradients significantly change during operation compared to Insulation Loss Testing 


\section{The Mock Heater Head}

- Key Mock Heater Head test components include

- Nickel heater head

- CSAF (Oxygen free high conductivity copper)

- Nickel and GRCop-84 conducting rods

- Nickel heater head modified from existing hardware

- Not stand alone hardware

- Requires heater preload to affix the heater head

- Requires additional hardware to use the conducting rods
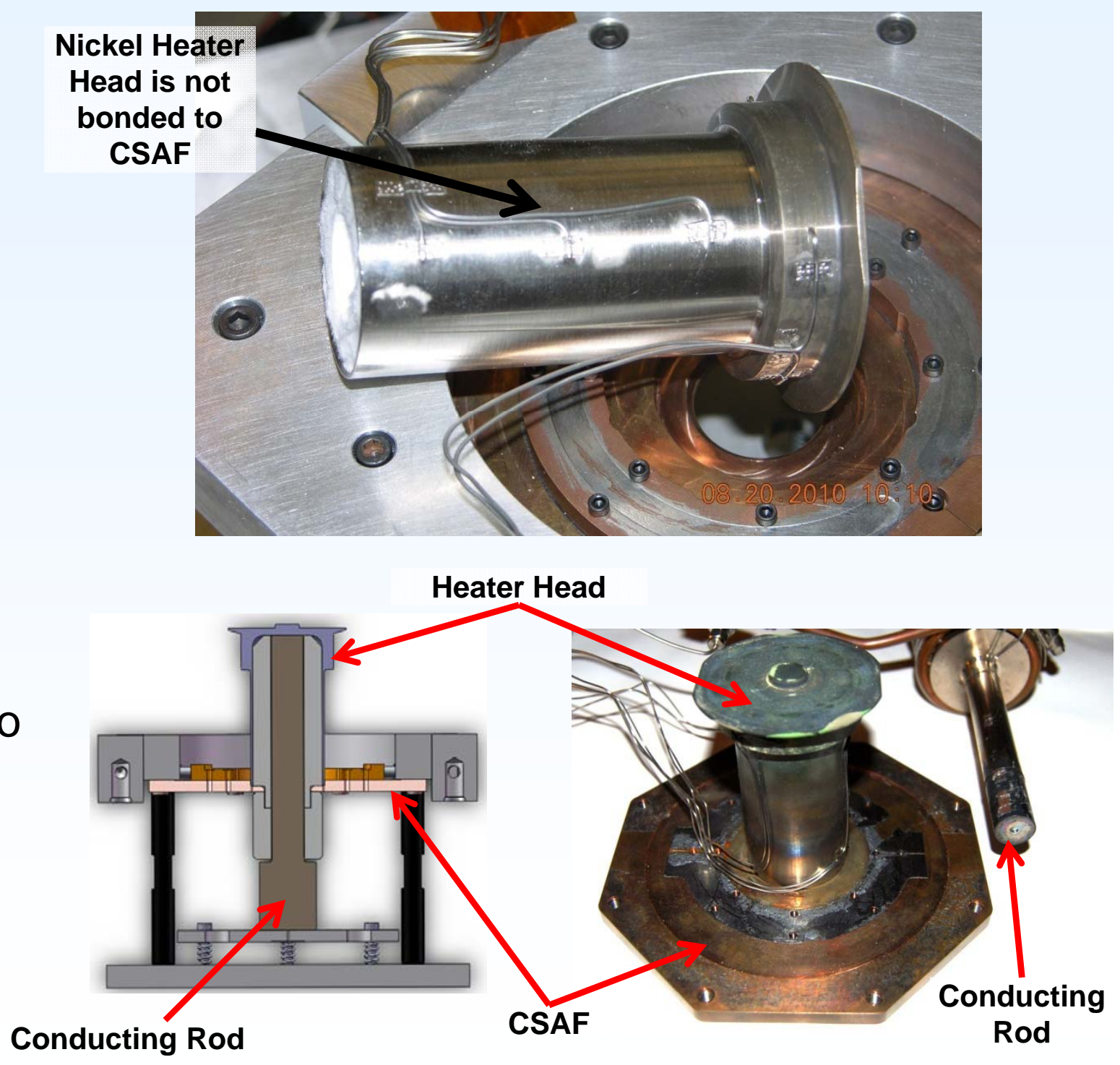


\section{Role of the Mock Heater Head}

- The Mock Heater Head served as a path finder and proof of concept for the Thermal Standard:

- Verified the test methodology and configuration

- Identified instrumentation locations for calculating heat conducted to the cold end

- Investigated the use of a conducting rod as a representative Stirling cycle and verified GRCop84 as a viable material option.

- Identified features for the heat collector and CSAF

- Validated use of an IR camera to measure temperatures on the exposed heater components

- Identified preferred test methods used for characterization

- Control off of hot-end temperature rather than heater temperature
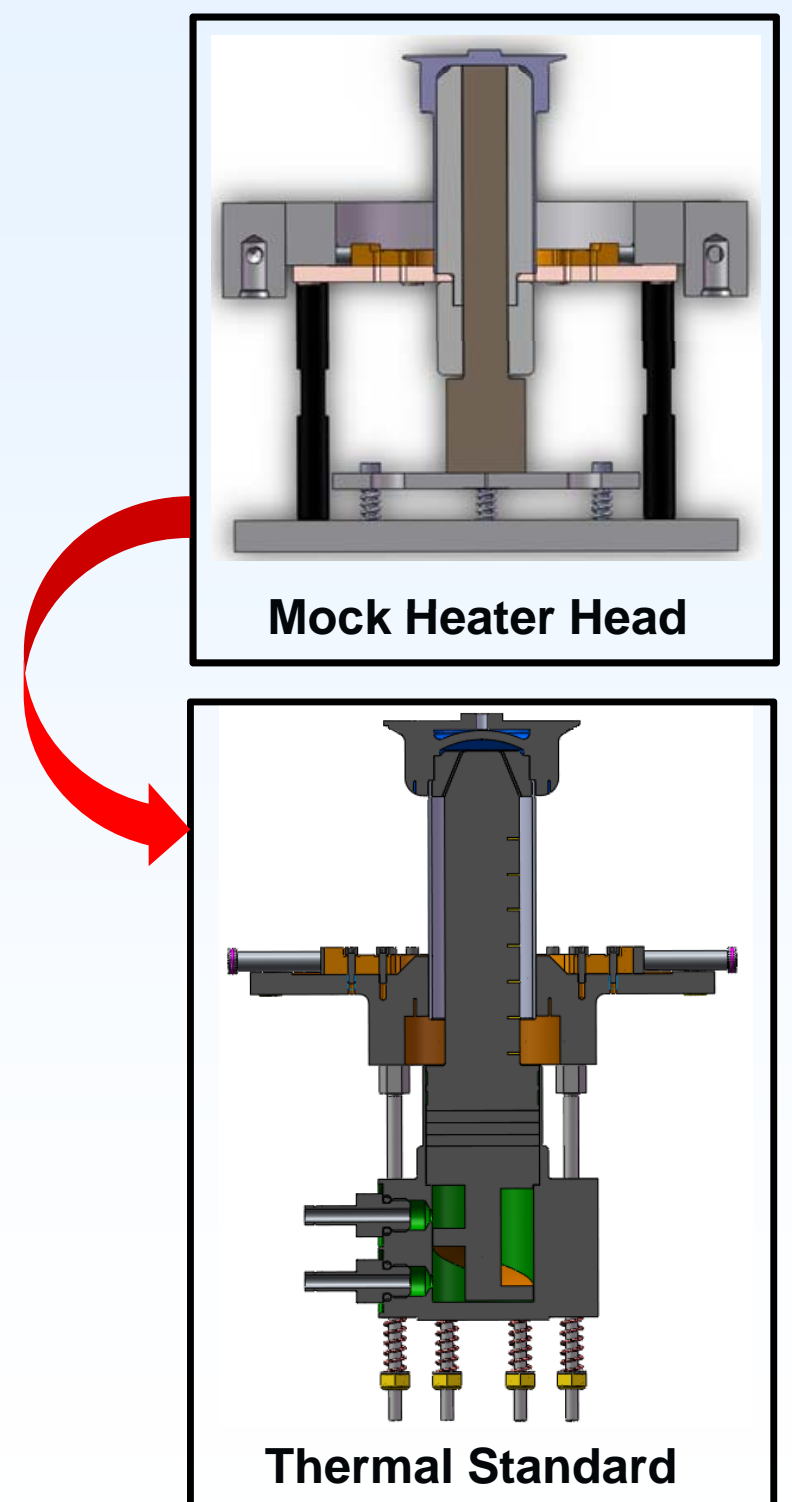

Glenn Research Center at Lewis Field 


\section{Test Configuration}

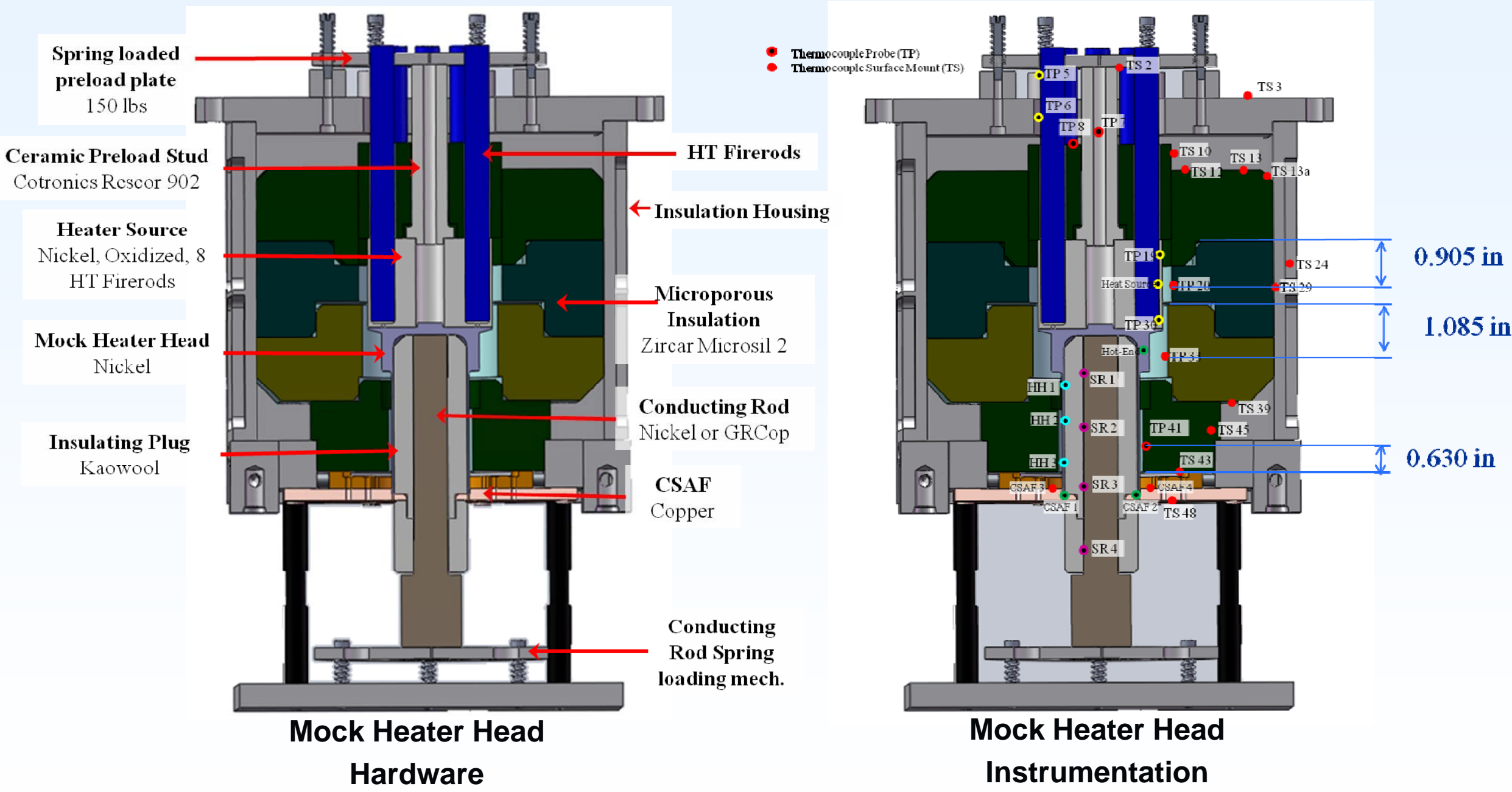




\section{Calculations}

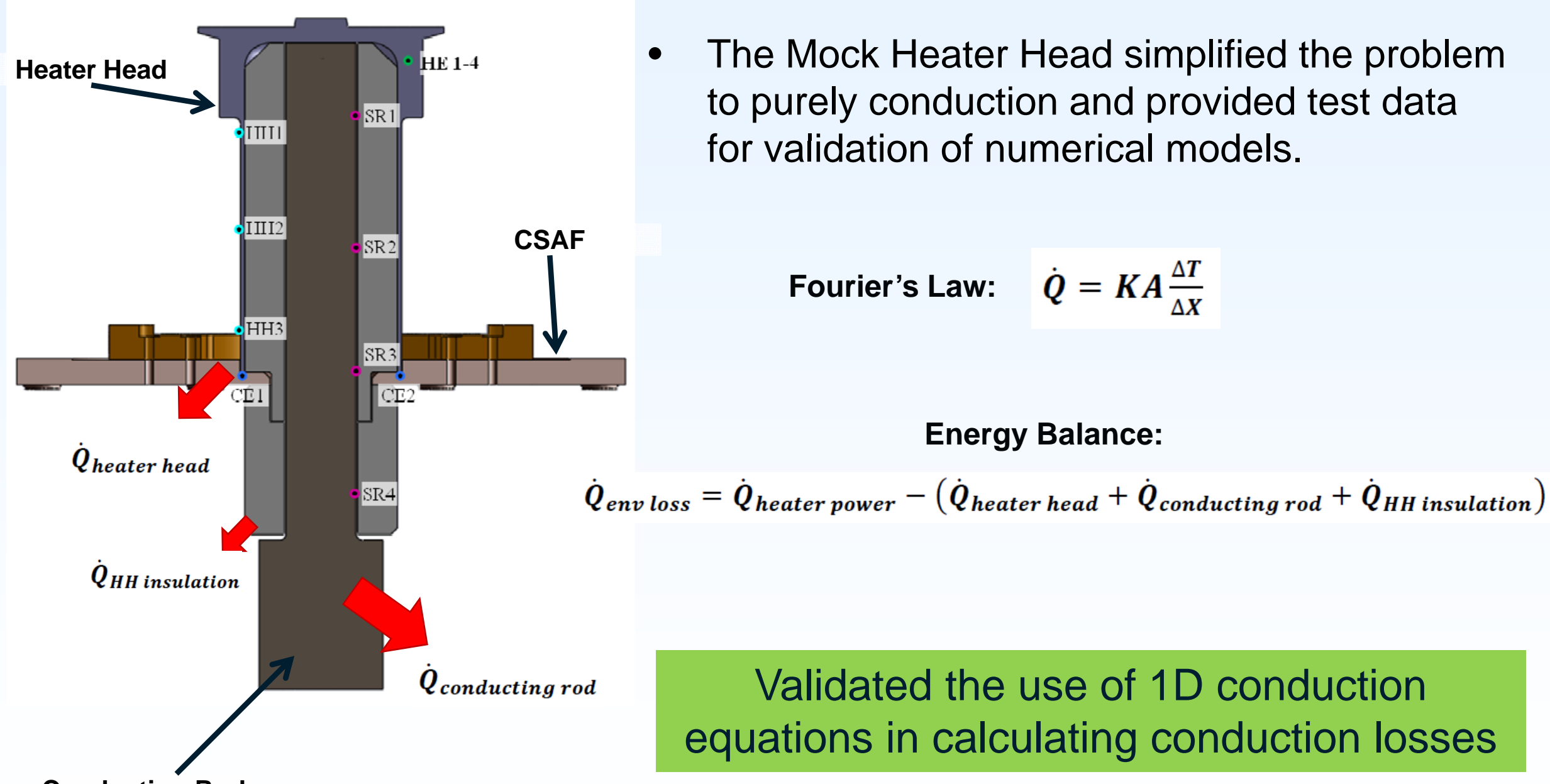

Conducting Rod 


\section{Testing}

\begin{tabular}{|l|l|l|l|}
\hline \multicolumn{4}{|c|}{ ASC-E2 Convertor Test Sequence } \\
\hline Test Title & $\begin{array}{l}\text { Interface } \\
\text { Material }\end{array}$ & $\begin{array}{l}\text { Piston } \\
\text { Status }\end{array}$ & $\begin{array}{l}\text { Environmental Loss } \\
\text { Calculation Method }\end{array}$ \\
\hline Alumina disk & Alumina disk & Stalled & Conduction calculation \\
\hline Thermal barrier & Ceramic paper & Stalled & Conduction calculation \\
\hline Nominal operation & Alumina disk & Moving & $\begin{array}{l}\text { Empirical model } \\
\text { Numerical models }\end{array}$ \\
\hline
\end{tabular}

Matching ASC-E2 Temperature Gradients
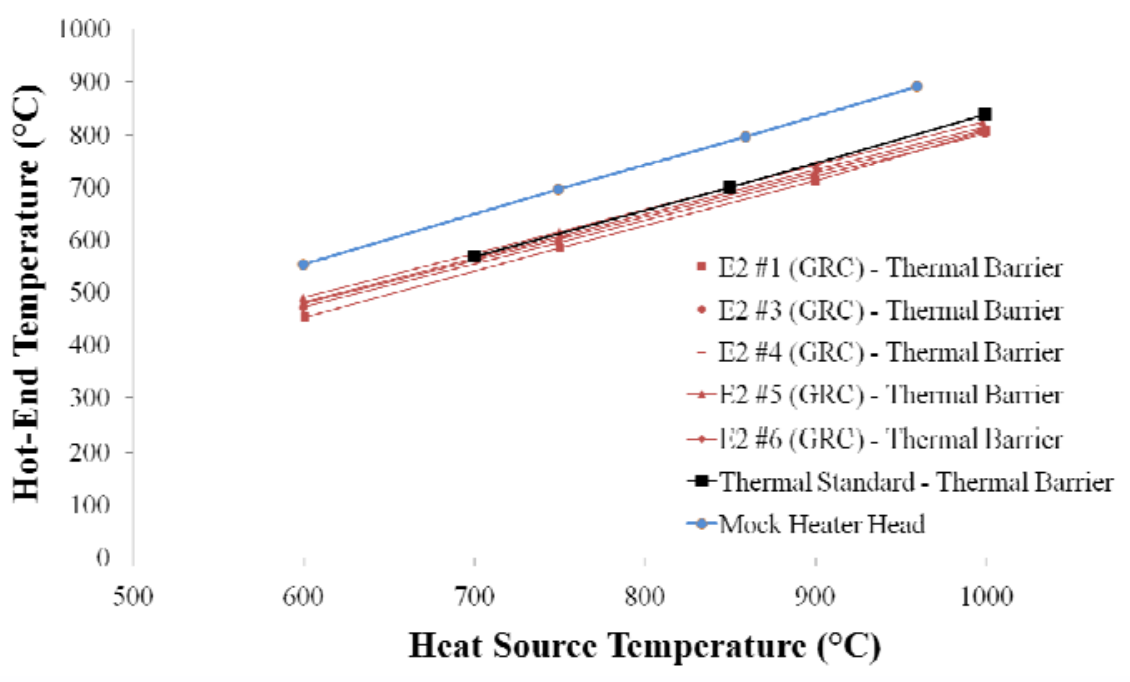

- Developed the test sequence and data reduction methods

- Identified preferred test methods used for characterization

- Temperature profiles didn't match as well as expected 


\section{Heat Flow Paths}

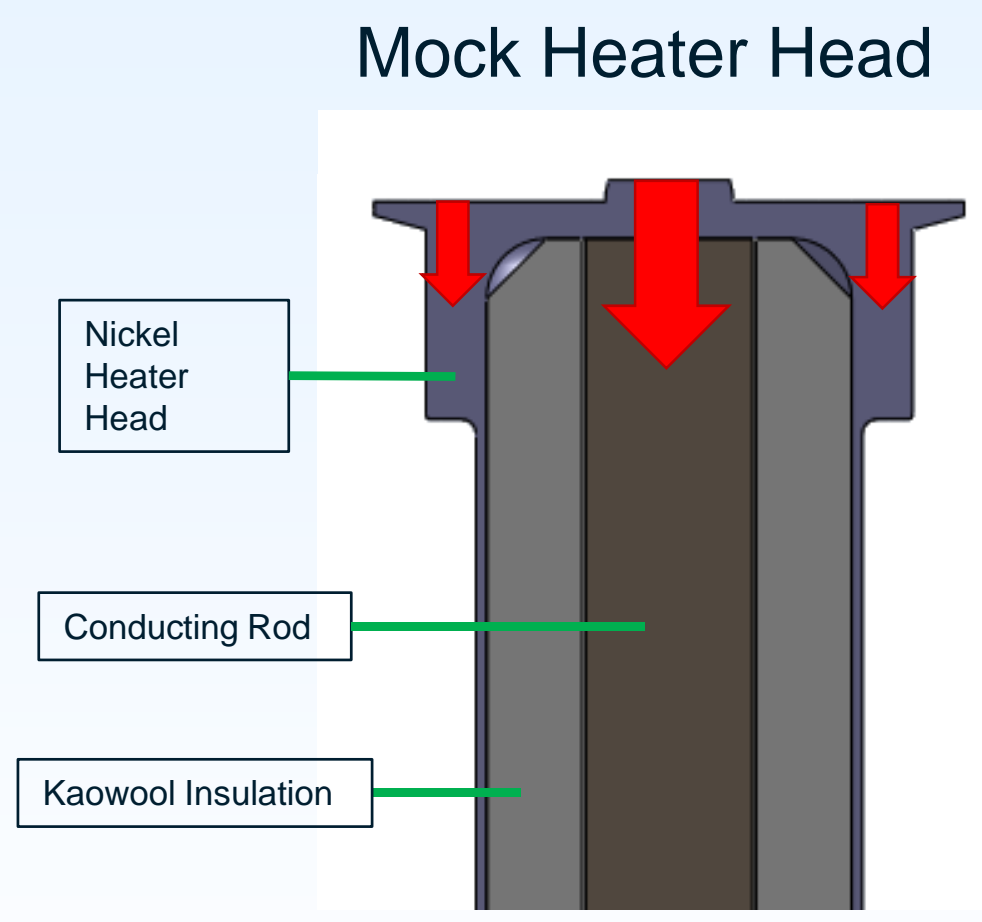

\section{Thermal Standard}

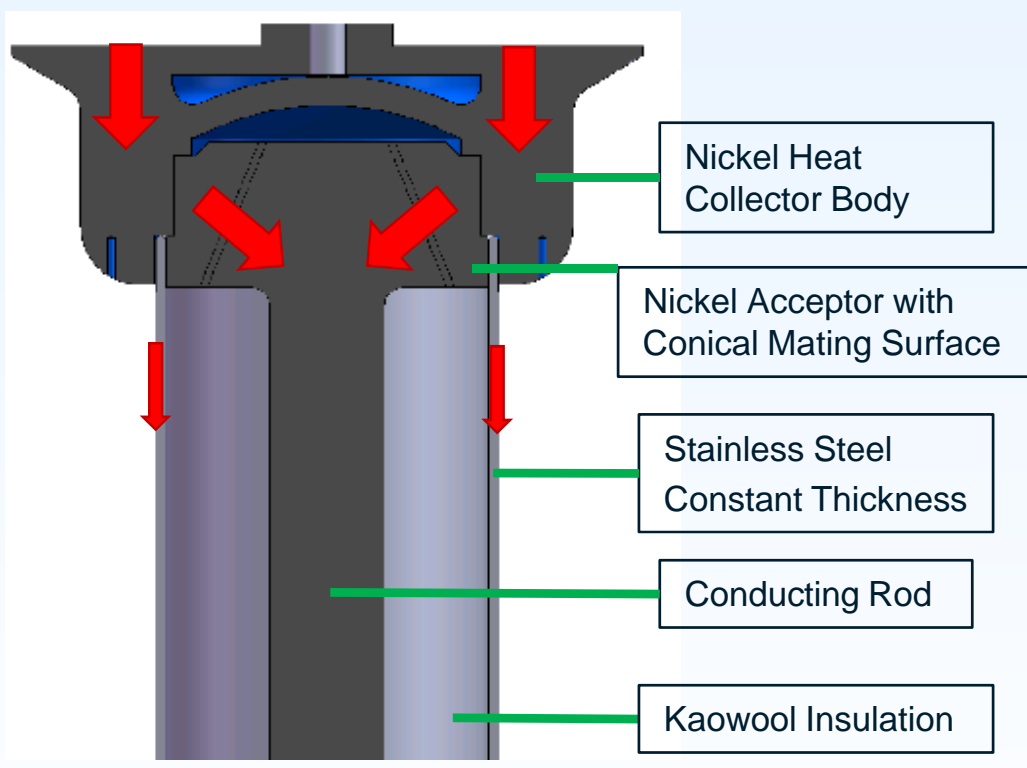

- Differences in heat flow paths effected the temperature profile

- Emphasized the need to have accurate heat flow paths in the Thermal Standard 


\section{The GRCop-84 Conducting Rod}

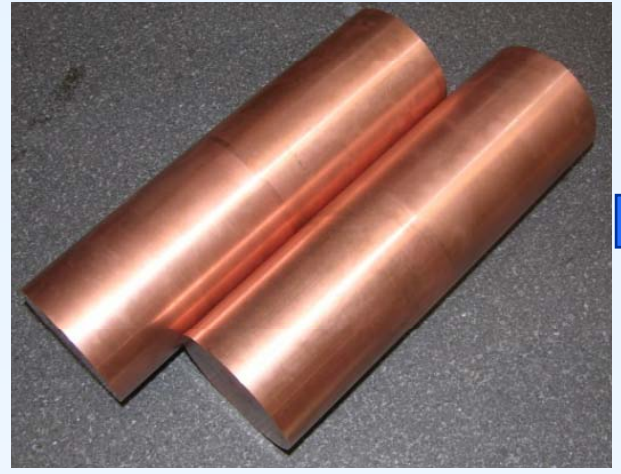

Raw GRCop-84 Billets

GRCop-84

\section{Advantages}

-Strength greater than copper

-Thermal Conductivity $80 \%$ of copper

\section{Concerns}

- Oxidation at elevated temperatures

- TC attachment

- Can it be nickel coated for oxidation protection?

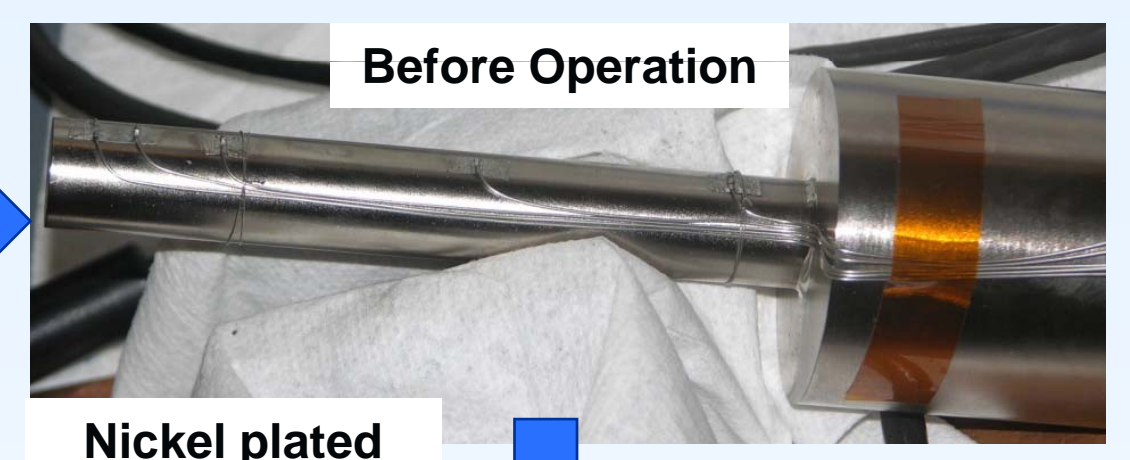

Nickel plated GRCop-84 rod

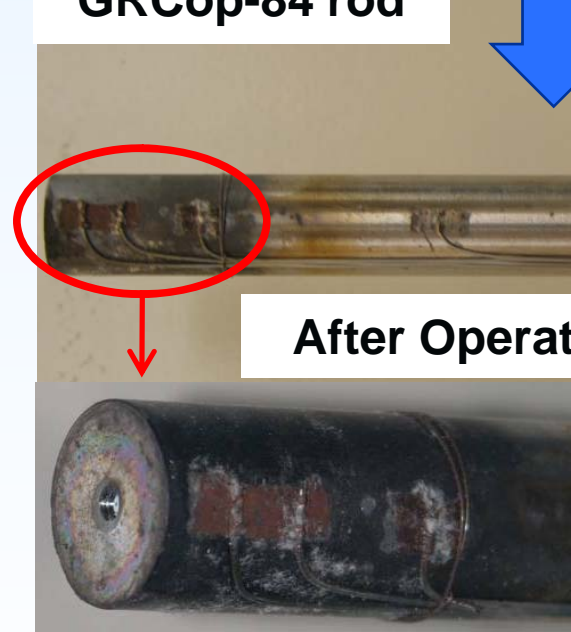

plating did not flake after 415 hours of operation at $500{ }^{\circ} \mathrm{C}$

- Verified GRCop-84 as viable material for conducting rod - Verified nickel plating as viable oxidation protection 


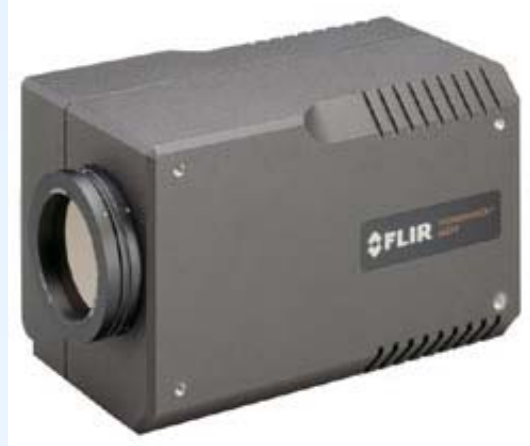

FLIR Thermal Camera

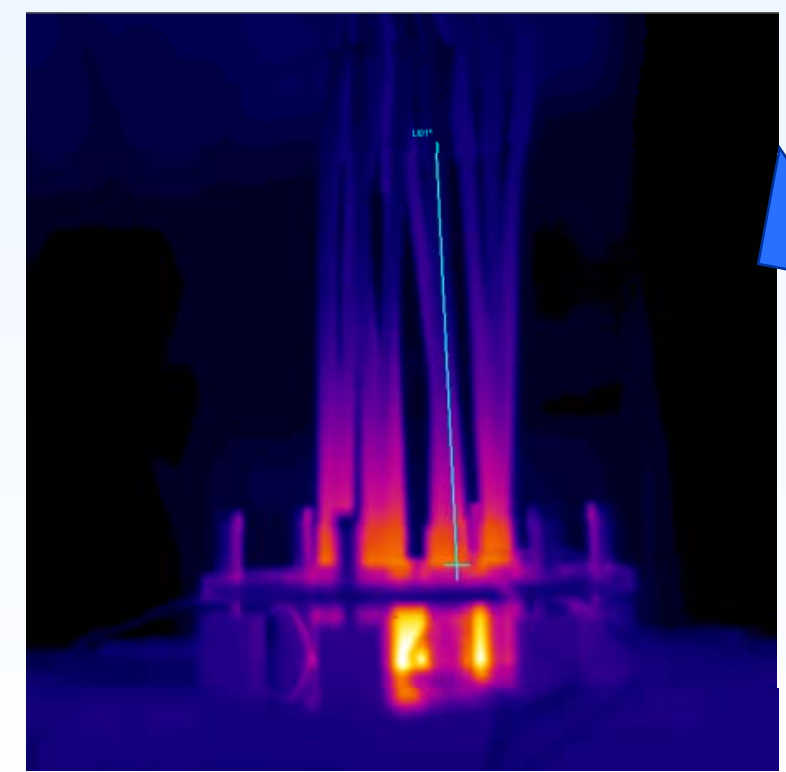

Thermal Image from FLIR Camera

\section{Thermal Imaging of Exposed Heater Components}

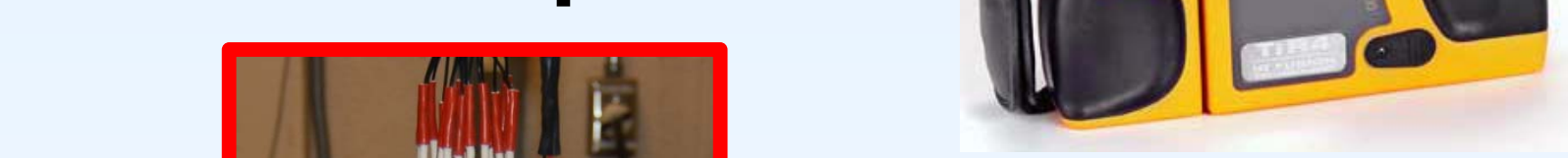

Fluke i45 Thermal Camera

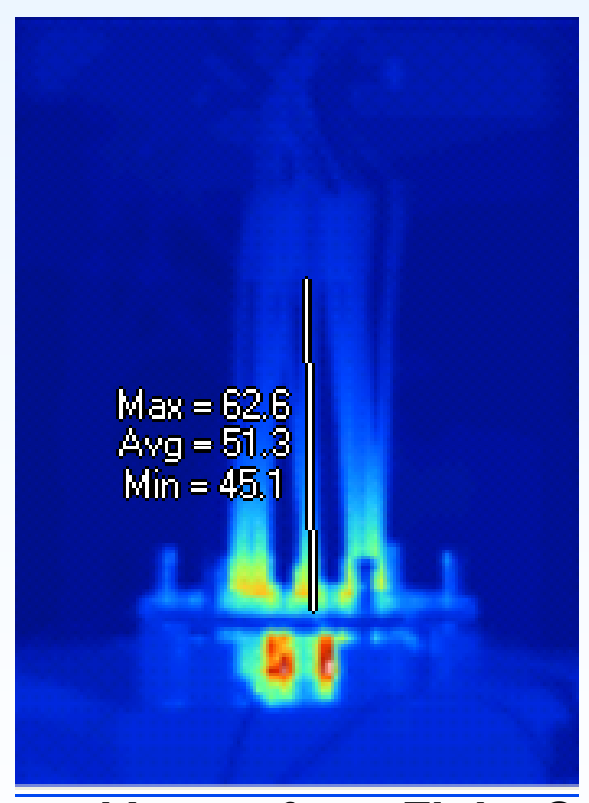

Mock Heater Head Test Setup Thermal Image from Fluke Camera

Identified and verified use of thermal imaging as a means of defining the thermal profile of the exposed heater components for numerical models 


\section{Conclusions}

- The Mock Heater Head served as a path finder and proof of concept in the development of the Thermal Standard as part of the Net Heat Input Investigation

- Verified the test methodology and configuration

- Identified instrumentation locations for calculating heat conducted to the cold end

- Investigated the use of a conducting rod as a representative Stirling cycle and verified GRCop-84 as a viable material option

- Identified features for the heat collector and CSAF

- Validated use of an IR camera to measure temperatures on the exposed heater components

- Identified preferred test methods used for characterization

- Control off of hot-end temperature rather than heater temperature

Results of the Mock Heater Head drove the design of the Thermal Standard 


\section{Acknowledgements and Required Disclaimer}

This work is funded through the National Aeronautics and Space Administration (NASA) Science Mission Directorate and the Radioisotope Power Systems Program Office. In addition, this work would not have been possible without the contributions of Jeff Schreiber, Scott Wilson and Wayne Gerber who assisted in design, setup, planning, and analysis.

Any opinions, findings, conclusions, or recommendations expressed in this article are those of the authors and do not necessarily reflect the views of NASA. 